\title{
Temperature and Precipitation Trend Analysis over the Last 30 Years in Southern Tigray Regional State, Ethiopia
}

\author{
Birhanu Hayelom ${ }^{1, *}$, Yingjun Chen ${ }^{2}$, Zinabu Marsie ${ }^{1}$ and Misiker Negash ${ }^{1}$ \\ ${ }^{1}$ UN Environment -Tongji Institute of Environment for Sustainable Development, College of \\ Environmental Science and Engineering, 20092 Shanghai, China; \\ zinabu.marsie@yahoo.com (Z.M.); mesekergashaw@yahoo.com (M.N.) \\ ${ }^{2}$ College of Environmental science and Engineering, Tongji University, 20092 Shanghai, China; \\ yjchentj@tongji.edu.cn \\ * Correspondence: brema2015@yahoo.com; Tel.: +86-13162396910
}

\begin{abstract}
Long term Precipitation and temperature variations are one of the main determinants of climate variability of one's area. The aim of this study is to determine trends variation in climatic elements of temperature and precipitation in the southern zone of Tigray regional state, Ethiopia. The station is assumed for the study of climatic records over southern zone of the region in detection for probable trends. The daily, monthly and annual precipitation totals and temperature observed at korem meteorological station were used for the period of 1981-2010 for Precipitation and 1985 - 2010 for minimum and maximum temperature. Summary of descriptive statistics and Mann Kendall test methods were employed for the observed data analysis to demonstrate any existence of possible trends. The main findings of the study indicated that the mean and maximum temperature had a general increasing trend; however, minimum temperature showed decreasing trend. In general annual temperature from 1985 2010 of the area showed a warming trend. Moreover analysis of the 30 years (1981-2010) annual precipitation showed a coefficient of variation ranging from $33.77-233 \%$. It indicated that the precipitation dissemination is not normal with large year to year variances.
\end{abstract}

Key word: temperature; precipitation; ethiopia; mann kendall; climate variability

\section{Introduction}

Africa is one of the most vulnerable continents to climate change and climate variability, a situation aggravated by the interaction of 'multiple stresses' occurring at various levels, and low adaptive capacity [1]. It is widely projected that as the planet warms, climate and weather variability will increase. Changes in the frequency and severity of extreme climate events and in the variability of weather patterns will have significant consequences for human and natural systems. Increasing frequencies of heat stress, drought and flooding events are projected for the rest of this century, and these are expected to have many adverse effects over and above the 
impacts due to changes in mean variables alone [2]. Warming of the climate system can result in very large corresponding changes in the occurrence of climate extremes. Temperature extremes may occur due to a shift in the whole distribution, where there is an increase in the entire temperature probability distribution, or to changes in the shape of the distribution, such as an increase in variability causing a widening of the distribution. Understanding the precise characteristics of changes in temperature distributions in response to background warming is an important aspect of fully understanding changes in heat extremes and their associated impacts on human and ecosystem health [3]

The equatorial and southern parts of eastern Africa have experienced a significant increase in temperature since the early 1980s. Seasonal average temperatures have also risen in many parts of eastern Africa in the last 50 years. Countries bordering the western Indian Ocean experienced warmer temperatures and more frequent heat waves between 1961 and 2008. Extreme precipitation changes over eastern Africa such as droughts and heavy rainfall have been experienced more frequently during the last 30-60 years. Continued warming in the Indian Ocean has been shown to contribute to more frequent East African spring and summer droughts over the past 30 years [4] Changes in climate variability and in the frequency of extreme events may have substantial impacts on the prevalence and distribution of pests, weeds, and crop and livestock diseases. For example, in the past, combinations of drought followed by high rainfall have led to wide-spread outbreaks of diseases such as Rift Valley fever and bluetongue in East Africa and of African horse sickness in South Africa [5, 6].

Climate change poses a huge challenge to Ethiopia and its people. The country is faced with increasingly unpredictable rains, and sometimes the complete failure of seasonal rains problems which are linked to climate change. It is a country with large differences across regions which are reflected in the country's climate vulnerability. The lowlands are vulnerable to increased temperatures and prolonged droughts which may affect livestock rearing. The highlands may suffer from more intense and irregular rainfall, leading to erosion, which together with higher temperatures leads to lower total agricultural production. This, combined with an increasing population, may lead to greater food insecurity in some areas. Hotspots of increased food insecurity in the future, due to climate change, are likely to include areas in Afar and Tigray, southern Oromia, the central Rift Valley, and the eastern lowlands [7].

The implication of the changing rainfall trends is that it will become increasingly important to put adaptation measures in place to manage and reduce the risks of changing rainfall on productive systems such as agriculture and forestry and to build resilience [4]. Decreasing the vulnerability of socio-economic sectors and ecological systems to natural climate variability through a more informed choice of policies, practices and technologies will, in many cases, reduce the long-term vulnerability of these systems to climate change [8,9].

Therefore this study aimed at determining the climate seasonal variability of temperature and precipitation variation trend analysis over the last 30 years in Southern Tigray regional state, Ethiopia. 


\section{Materials and Methods}

\subsection{Description Study Area}

Southern Tigray zone particularly Korem metrological station is located in korem town which is detached woreda in northern Ethiopia. Situated on the eastern edge of the Ethiopian highlands in the Debubawi (Southern) Zone of the Tigray Region, this town has a latitude and longitude of $12^{\circ} 30^{\prime} \mathrm{N} 39^{\circ} 31^{\prime} \mathrm{E}$ with an elevation of 2539 meters above sea. This metrological station is used as a core weather observation for the southern zone and the region at large

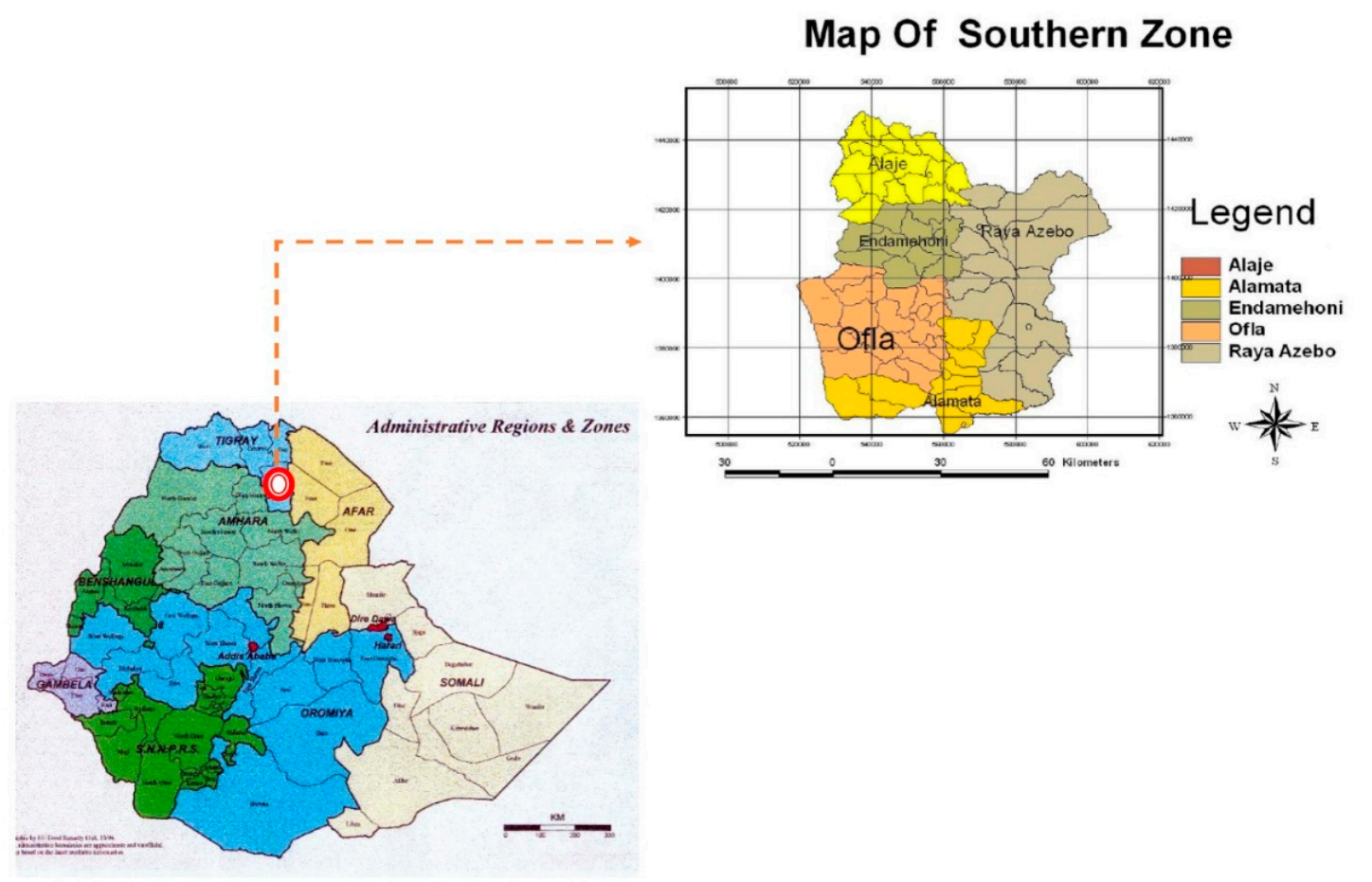

Figure 1: Geographical map of the Study Area

\subsection{Materials}

Observational data for daily maximum temperature, daily minimum temperature, daily mean temperature and annual rainfall recorded at southern Tigray, Korem weather station. In the region have been obtained different class of meteorological stations. This weather station is using as the center for weather condition reading and prediction for the southern zone of the region. The reason why Temperature and precipitation were picked to study is because of the area is highly dependent on agriculture and affected by drought for many years. Climate change variability in the study area is obvious. In this study, the annual, periodic and monthly precipitation totals and temperature measured at korem meteorological observation station were used for the period of 1981-2010 for Precipitation and from 1985 - 2010 for temperature. 


\subsection{Method of data analysis}

Monthly and annually mean of daily time series data of climatic parameters, viz. temperature (maximum and minimum), precipitation were computed using excel spreadsheet. To make clear the distance from the average, the average precipitation amount was calculated over the 30-years period to be able to examine precipitation statistics. Decretive statistics were used to analyze the Mean, Standard Error, Median, Standard Deviation, Sample Variance, Kurtosis, Skewness, Range, Minimum and Maximum (temperature), Coefficient of variance and Confidence Level (95.0\%) of temperature and precipitation were determined.

For the Annual and monthly precipitation and temperature data analysis the trend detection methods were used. Mann-Kendall (Mann 1945; Kendall, 1975) statistical method was applied to annual and seasonal distribution of rainfall and temperature to detect any possible trends in the data over the study period. This is a non-parametric statistical test well suited to measure trend in data over time [10]. Positive (+) values indicate an increase over time while, negative $(-)$ values indicate decrease. The test observes whether a random response variable monotonically increases or decreases with time.

\section{Result and Discussion}

\subsection{Precipitation}

Precipitation trends of Korem metrological station in southern Tigray regional state was analyzed of its 30 years annual precipitation data. The descriptive statistics of annual precipitation such as the coefficient of variation $(\mathrm{CV})$, coefficients of skewness $(\mathrm{Cs})$ and coefficients of kurtosis (Ck) are discussed in Table1) and Mann Kendall trend test was also employed for trend detection. Result of Mann Kendall trend analysis also presented in (Table 4). So from the analysis it is observed that the average monthly precipitation coefficient of variation ranging from $33.77-233 \%$ (Table1). According to [11], CV is used to classify the degree of variability of rainfall events as less $(\mathrm{CV}<20)$, moderate $(20<\mathrm{CV}<30)$, high $(\mathrm{CV}>$ 30), very high $\mathrm{CV}>40 \%$ and $\mathrm{CV}>70 \%$ indicate extremely high inter-annual variability of rainfall. Based on this, from the observed data considered that all the months had above $30 \%$ coefficient of variation $(\mathrm{CV})$ highlighting the high variability of precipitation over the zone (Table1).

In the study area for the annual totals as well as for the months the coefficient of variation (CV) was greater than $\mathrm{CV}=5 \%$. The highest values of coefficient of kurtosis were found in October (12.4). Despite the low values for the degree of skewness were found in August (-0.2). From the statistical analysis (Table1), the results indicated that the data were normally distributed despite of slight negative skewness. According to the results, almost all months have represented higher CV (coefficient of variation) which means that all months have homogenous character in terms of precipitation variations. The mean annual precipitation of the study region is slightly low, ranging from $620 \mathrm{~mm}$ to $1411 \mathrm{~mm}$ (Figure 2). 
Table1: Statistical summary of monthly precipitation for the Korem Station from 1981-2010

\begin{tabular}{lrrrrrrrrrrrrr}
\hline & Jan & Feb & Mar & Apr & May & Jun & Jul & Aug & Sep & Oct & Nov & Dec \\
\hline Count & 30 & 30 & 30 & 30 & 30 & 30 & 30 & 30 & 30 & 30 & 30 & 30 \\
Mean & 22.98 & 13.6 & 60.2 & 81 & 61.13 & 46.6 & 231.4 & 280.4 & 82.12 & 47.7 & 20.6 & 44.3 \\
Std E & 6.702 & 5.8 & 9.21 & 11.2 & 9.5333 & 6.44 & 16.89 & 17.29 & 6.945 & 11.5 & 5.68 & 10.3 \\
Median & 2.55 & 0.7 & 42.6 & 61.2 & 44.1 & 46.8 & 209.6 & 306.1 & 85.8 & 35.5 & 6.75 & 18.4 \\
SD & 36.71 & 31.8 & 50.5 & 61.4 & 52.216 & 35.3 & 92.52 & 94.71 & 38.04 & 63.1 & 31.1 & 56.3 \\
SV & 1348 & 1009 & 2547 & 3764 & 2726.5 & 1244 & 8560 & 8969 & 1447 & 3988 & 967 & 3170 \\
Kurtosis & 5.336 & 8.67 & 0.56 & 1.37 & -0.802 & -1.3 & 0.76 & -0.39 & 3.382 & 12.4 & 5.75 & 0.21 \\
Skewness & 2.097 & 3.01 & 1.06 & 1.35 & 0.6977 & 0.22 & 1.043 & -0.6 & 1.297 & 3.14 & 2.18 & 1.19 \\
Minimum & 0 & 0 & 0 & 12.3 & 0 & 0 & 101.8 & 55.9 & 32.2 & 0 & 0 & 0 \\
Maximum & 159.6 & 127 & 182 & 242 & 165.3 & 112 & 462 & 419.2 & 212.3 & 323 & 137 & 172 \\
CI (95.0\%) & 13.71 & 11.9 & 18.8 & 22.9 & 19.498 & 13.2 & 34.55 & 35.36 & 14.2 & 23.6 & 11.6 & 21 \\
CV \% & 159.8 & 233 & 83.8 & 75.7 & 85.418 & 75.7 & 39.99 & 33.77 & 46.32 & 132 & 151 & 127 \\
\hline
\end{tabular}

SD: Standard Deviation, StdE: Standard Error, SV: Sample variance, CI: Coefficient of Interval,

CV Coefficient Variance

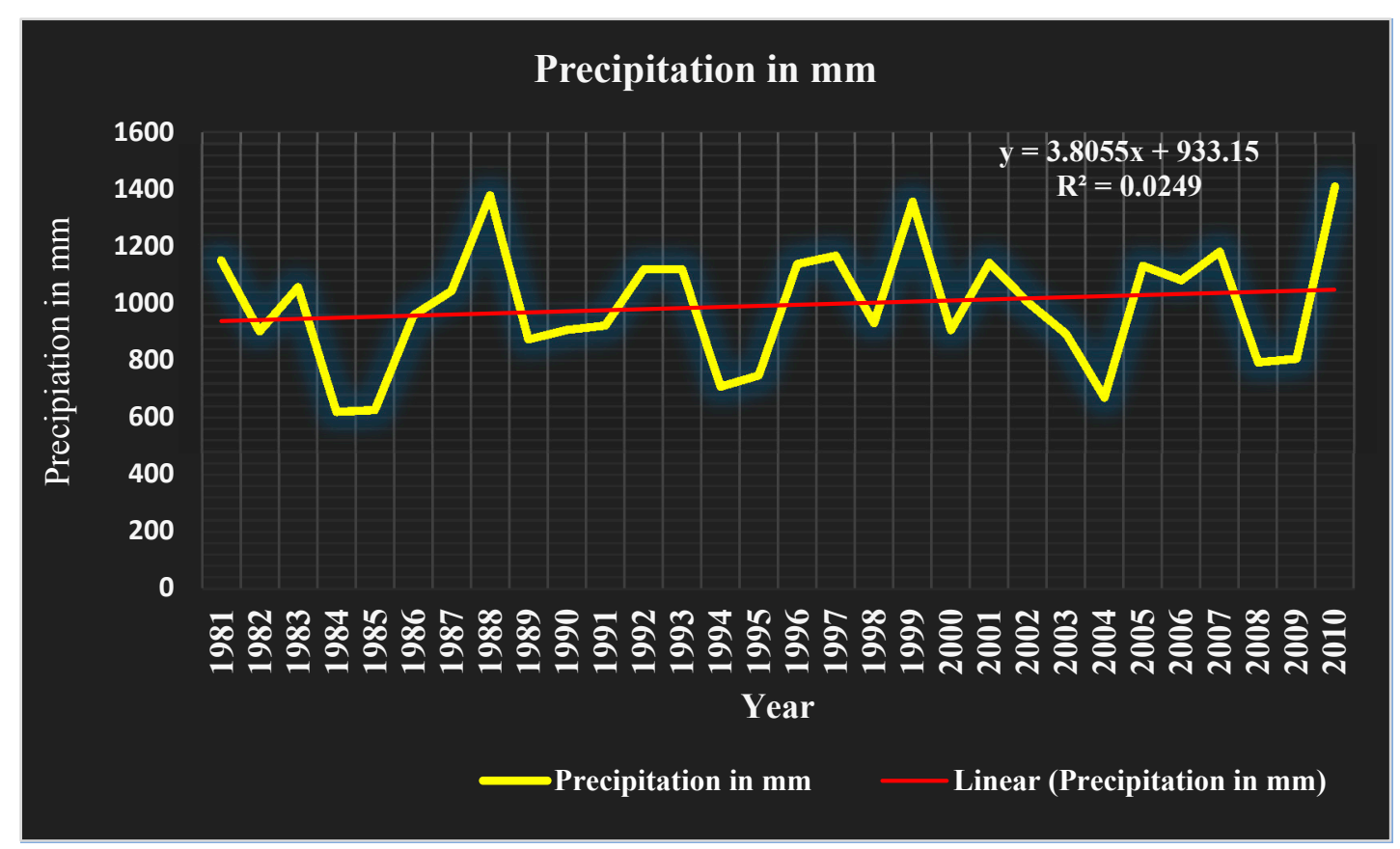

Figure 2: Annual Precipitation trend of Korem Metrological station from 1981-2010.

The result indicated that the amount of precipitation in the region is extremely variable. It is similar to the Ethiopian climate variability. Ethiopian rainfall is highly variable, especially in the area where agricultural dependent rural people are densely populated (highland regions). Moreover, rainfall variability is also higher for most of the stations in the area where agricultural activities are the main livelihood. For the highest rainfall dependent Ethiopian agriculture, the amount and distribution of the rainfall during the crop growing seasons are critical [12]. In Ethiopia, the start and end of the rain, its patterns of distribution, frequency and probability of dry spells in the growing season, most commonly summer, are key factors affecting planning, performance, and management of agricultural operations. This is because 
unusual rainfall amount and distributions usually lead to poor harvest and/or complete crop failure and shortage of pasture and animal feeds [13].

\subsection{Mann Kendall Temperature and Precipitation}

The non-parametric test, Mann Kendall method was used to analyze if there is a monotonic upward or downward trend of the variable of notice over time. The analysis results indicates that most of the station's consecutive annual precipitation years are positively related (Table 2). A description of the applied statistical test results are presented in (Table 2). Statistically, significant trends are detected for precipitation on monthly basis and also this result is statistically significant at $95 \%$ confidence limit during the period of 1981-2010. Trend analyses were also showed on monthly and periodic precipitation data (Table 2). Precipitation patterns for periods denote significant positive trends at $95 \%$ confidence level. However there is considerable amount of precipitation decrease for winter which is statistically significant at $90 \%$ confidence limit during the period of 1981-2010. Precipitation Trend analysis showed higher during summer while low during winter.

Regarding temperature, significant trends are found for maximum temperature data on annual and monthly basis while negative trends are detected for minimum temperature for the period of observed from 1985-2010 (Table 2). In general, annual maximum temperature trend showed a warming trend while the minimum temperature trend is showed a cooling trend and also both results are statistically significant at $95 \%$ confidence limit during the period of 1985-2010. The increase in annual temperature observed in the study area is caused by increase in summer months, which compensate the slight decrease in the other seasons especially autumn months.

Table 2: Monthly Mann-Kendall results of precipitation and Temperature for the area

\begin{tabular}{|c|c|c|c|c|c|c|c|c|c|}
\hline \multirow{2}{*}{$\begin{array}{l}\text { Time } \\
\text { series }\end{array}$} & \multicolumn{3}{|c|}{$\begin{array}{l}\text { Annual } \\
\text { Precipitation(1981-2010) }\end{array}$} & \multicolumn{3}{|c|}{$\begin{array}{l}\text { Maximum } \\
\text { Temperature(1985-2010) }\end{array}$} & \multicolumn{3}{|c|}{$\begin{array}{l}\text { Minimum Temperature } \\
(1985-2010)\end{array}$} \\
\hline & MKZ & Signific. & $\begin{array}{l}\text { Sen's } \\
\text { Slope }\end{array}$ & MKZ & Signific. & $\begin{array}{l}\text { Sen's } \\
\text { Slope }\end{array}$ & MKZ & Signific. & $\begin{array}{l}\text { Sen's } \\
\text { Slope }\end{array}$ \\
\hline January & 1.84 & $*$ & 0.038 & 1.84 & $*$ & 0.038 & -1.413 & & -0.084 \\
\hline February & 1.38 & & 0.039 & 1.38 & & 0.039 & -2.074 & $*$ & -0.135 \\
\hline March & 2.92 & $* *$ & 0.054 & 2.92 & $* *$ & 0.054 & -2.669 & $* *$ & -0.129 \\
\hline April & 2.93 & $* *$ & 0.033 & 2.93 & $* *$ & 0.033 & -3.223 & $* *$ & -0.1 \\
\hline May & 2.76 & $* *$ & 0.026 & 2.76 & $* *$ & 0.026 & -2.562 & $*$ & -0.127 \\
\hline June & 0.18 & & 0 & 0.18 & & 0 & -1.7 & $*$ & -0.12 \\
\hline July & 2.69 & $* *$ & 0.028 & 2.69 & $* *$ & 0.028 & -2.716 & $* *$ & -0.053 \\
\hline August & 2.38 & $*$ & 0.021 & 2.38 & $*$ & 0.021 & -3.323 & $* * *$ & -0.056 \\
\hline September & 1.64 & & 0.017 & 1.64 & & 0.017 & -2.427 & $*$ & -0.095 \\
\hline October & 1.61 & & 0.016 & 1.61 & & 0.016 & -2.736 & $* *$ & -0.133 \\
\hline November & 2.23 & * & 0.026 & 2.23 & * & 0.026 & -2.404 & $*$ & -0.143 \\
\hline December & 1.08 & & 0.024 & 1.08 & & 0.024 & -1.236 & & -0.087 \\
\hline
\end{tabular}

ZMK is Mann-Kendall trend test, Slope (Sen's slope) is the change (days)/annual; *** is statistically significant at 0.05 and 0.1 probability level; ns is non-significant trend at 0.1 . 


\section{Mann Kendall Annual Precipiation}

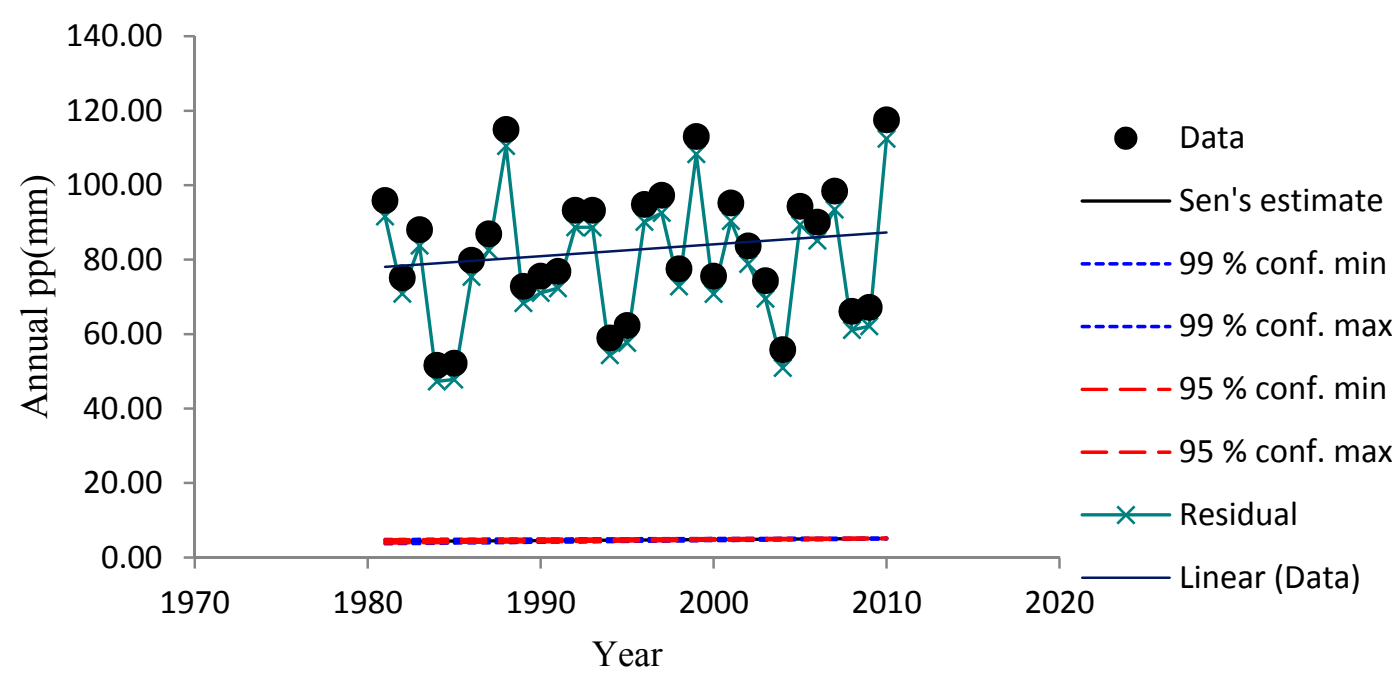

Figure 3: Total Annual precipitation showing Kendall slope and Linear regression slopes for Korem Station for the period of 1981-2010.

The means of the residuals are significantly at $5 \%$ significance level, indicating that it's from a random distribution. This suggests that a linear model may be applied to the annual Precipitation total, although there is large discrepancy between the slope values obtained using the Kendall method and the linear regression for the station during the periods from 1981-2010 (Figure 3).

\subsection{Temperature trend analysis}

Air temperature has crucial impact on the water cycle in the study area. The observed data was analyzed for the period 1985-2010. So that the analyzed temperature recorded data and the employed descriptive statistics which are the mean, standard deviation (SD), minimum, maximum, median, skewness, kurtosis and coefficient of variation (CV) are given in (Table 3) and (Table 4) and the maximum and minimum temperature trend analysis are presented in (Figure 4) and (Figure 5) respectively. (Figure 4) Represents the mean annual maximum temperature and its trend in the period of under examination. Using a linear regression model, the rate of change is defined by the slope of regression line which in this case is about 0.0013 ${ }^{\circ} \mathrm{C} / 26$ year during the period of $1985-2010$. This finding is not similar to global warming rate which is estimated $0.6{ }^{\circ} \mathrm{C}$ for the past century. This result shows that approaching to global warming study has important impact on the regional climate in the study area for the last two decades.

The slope of the whole months indicates that a positive value inferring rise in the mean monthly temperature. The mean, minimum and maximum temperature has recorded in the months of January and June respectively in the station. Furthermore, January and June were the months of high variations of mean monthly temperature recorded. Besides, May was the month of high deviation of temperature occurrence (Table 3). There is also a positive correlation between the 
monthly mean temperature record and the time period. This might be the case that temperature is increasing from time to time in the area as a result of global climate change.

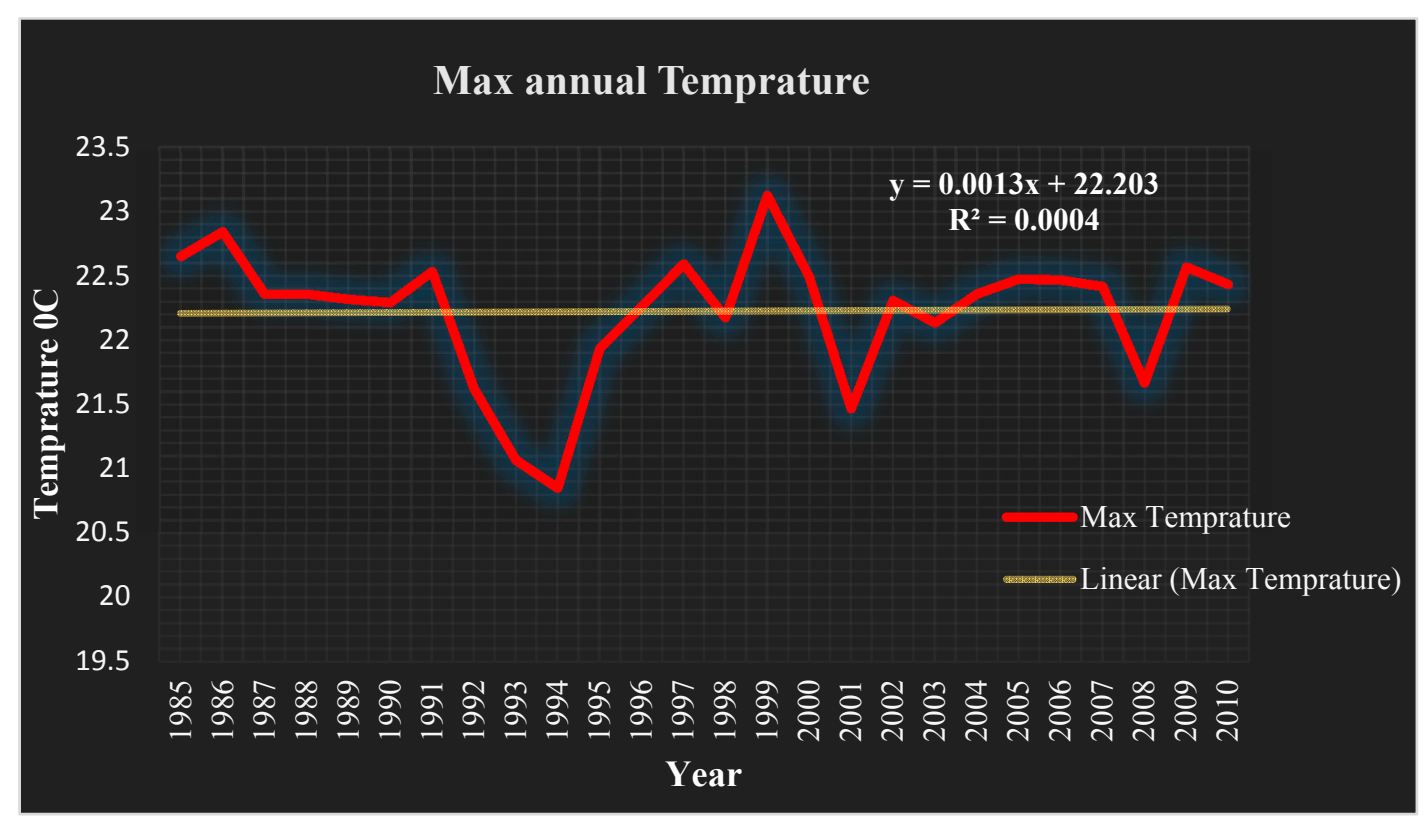

Figure 4: Maximum Annual temperature trend for the period 1985-2010

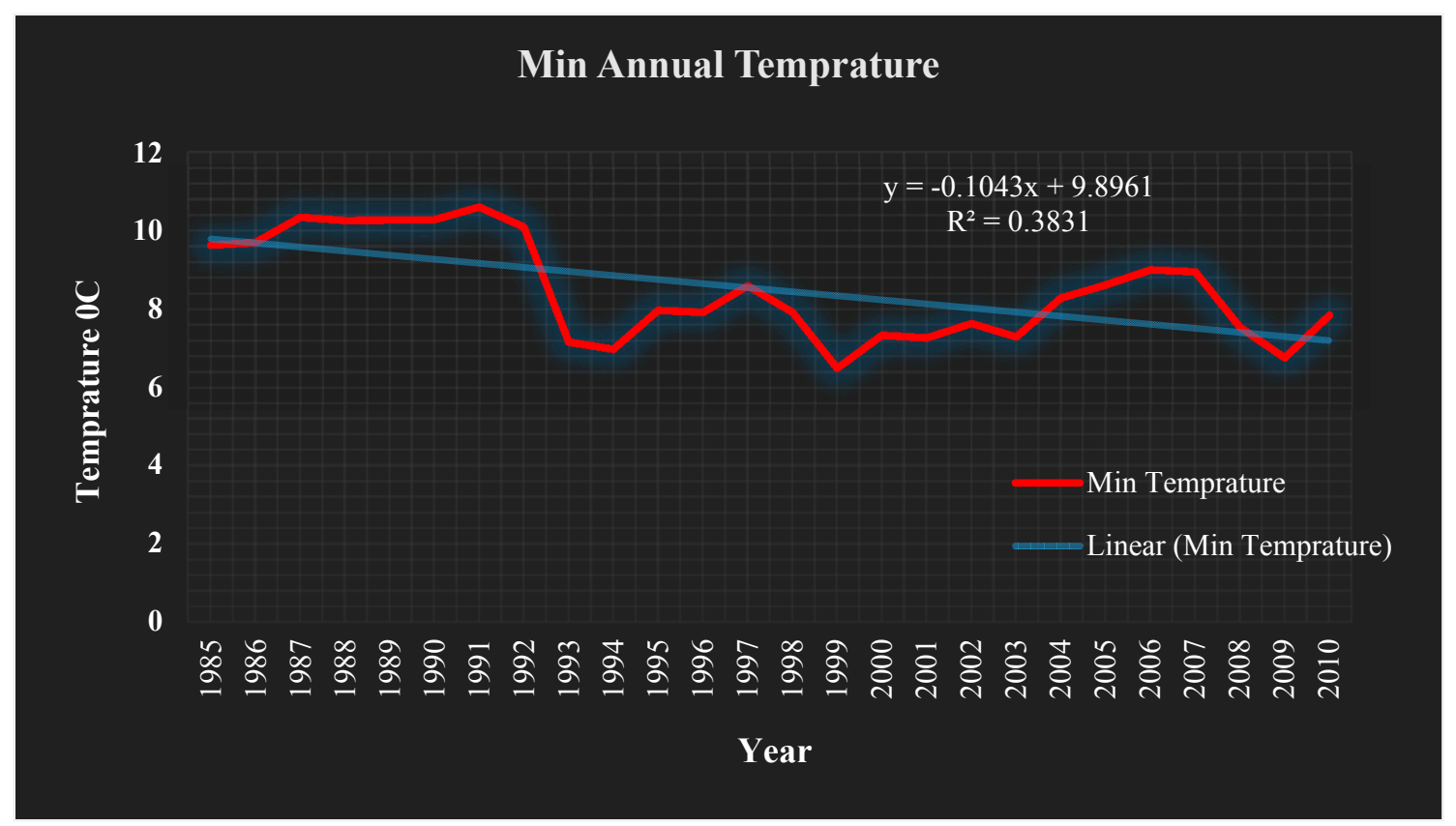

Figure 5: Minimum Annual temperature trend for the period 1985-2010 
Table 3: Statistical summary of monthly Mean Maximum temperature for the station from 1985 -2010 .

\begin{tabular}{lccccccccccccc}
\hline & Jan & Feb & Mar & Apr & May & Jun & Jul & Aug & Sep & Oct & Nov & Dec \\
& & & & & & & & & & & & \\
\hline Count & 26 & 26 & 26 & 26 & 26 & 26 & 26 & 26 & 26 & 26 & 26 & 26 \\
Mean & 19.8 & 22 & 22.3 & 22.7 & 24.3 & 25.4 & 22.9 & 22.4 & 22.9 & 21.6 & 20.92 & 19.69 \\
Std E & 0.2 & 0.3 & 0.22 & 0.17 & 0.27 & 0.19 & 0.16 & 0.14 & 0.16 & 0.23 & 0.233 & 0.143 \\
Median & 20 & 21 & 22.3 & 22.8 & 24.5 & 25.4 & 22.8 & 22.3 & 22.9 & 21.6 & 20.9 & 19.55 \\
SD & 1.04 & 1.8 & 1.1 & 0.86 & 1.39 & 0.96 & 0.83 & 0.7 & 0.81 & 1.2 & 1.189 & 0.73 \\
SV & 1.07 & 3.2 & 1.22 & 0.74 & 1.92 & 0.91 & 0.68 & 0.49 & 0.65 & 1.43 & 1.413 & 0.532 \\
Kurtosis & -0.9 & 10 & 0.84 & -0.34 & 1.35 & -0.7 & 3.17 & 1.39 & 0.56 & 1.79 & 2.435 & 0.103 \\
Skewness & -0.3 & 2.6 & -0.7 & -0.46 & -1.1 & 0.18 & 1.43 & 0.1 & 0.88 & 0.09 & 0.962 & 0.509 \\
Min & 17.8 & 19 & 19.5 & 20.9 & 20.8 & 23.7 & 21.7 & 20.6 & 21.8 & 18.8 & 19 & 18.5 \\
Max & 21.5 & 29 & 24.2 & 24.2 & 26.4 & 27.2 & 25.2 & 24.1 & 24.9 & 24.7 & 24.6 & 21.5 \\
CI(95.0\%) & 0.42 & 0.7 & 0.45 & 0.35 & 0.56 & 0.39 & 0.33 & 0.28 & 0.33 & 0.48 & 0.48 & 0.295 \\
CV\% & 5.2 & 8.2 & 4.5 & 3.8 & 5.7 & 3.8 & 3.6 & 3.1 & 3.5 & 5.5 & 5.7 & 3.7 \\
\hline
\end{tabular}

SD: Standard Deviation, StdE: Standard Error, SV: Sample variance, CI: Coefficient of Interval, CV Coefficient Variance

Table 4: Statistical summary of monthly Mean minimum temperature for the station from 1985 -2010 .

\begin{tabular}{lrrrrrrrrrrrrr}
\hline & Jan & Feb & Mar & Apr & May & Jun & Jul & Aug & Sep & Oct & Nov & Dec \\
& & & & & & & & & & & & \\
\hline Mean & 5.75 & 5.88 & 8.23 & 9.9 & 10 & 11.4 & 12.6 & 12 & 9.315 & 6.64 & 4.981 & 4.99 \\
Std E & 0.44 & 0.48 & 0.4 & 0.3 & 0.32 & 0.37 & 0.15 & 0.16 & 0.275 & 0.34 & 0.473 & 0.49 \\
Median & 5.9 & 6 & 8.65 & 10 & 10.1 & 11.1 & 12.5 & 11.9 & 9.35 & 6.9 & 5.15 & 4.7 \\
SD & 2.26 & 2.46 & 2.03 & 1.3 & 1.63 & 1.88 & 0.77 & 0.8 & 1.401 & 1.72 & 2.411 & 2.51 \\
SV & 5.13 & 6.05 & 4.11 & 1.7 & 2.66 & 3.55 & 0.59 & 0.65 & 1.962 & 2.97 & 5.815 & 6.31 \\
Kurtosis & -0.5 & -0.9 & 0.25 & -0 & -0.9 & -1.2 & 1.11 & 1.47 & -0.46 & -1.4 & -0.51 & -0.41 \\
Skewness & -0.5 & -0.3 & -0.9 & -1 & -0.2 & 0.12 & 0.89 & -0.1 & -0.01 & -0.2 & -0.16 & -0.1 \\
Minimum & 0.3 & 1.7 & 3.4 & 7.2 & 7.1 & 8.5 & 11.5 & 9.9 & 6.7 & 3.8 & 0.2 & -0.7 \\
Maximum & 8.9 & 9.5 & 10.7 & 12 & 12.4 & 14.3 & 14.8 & 13.9 & 11.7 & 9.2 & 10 & 9.2 \\
Count & 26 & 26 & 26 & 26 & 26 & 26 & 26 & 26 & 26 & 26 & 26 & 26 \\
CI (95.0\%) & 0.91 & 0.99 & 0.82 & 0.5 & 0.66 & 0.76 & 0.31 & 0.33 & 0.566 & 0.7 & 0.974 & 1.01 \\
CV\% & 39.4 & 41.8 & 24.6 & 13 & 16.3 & 16.5 & 6.08 & 6.72 & 15.04 & 25.9 & 48.42 & 50.3 \\
\hline
\end{tabular}

SD: Standard Deviation, StdE: Standard Error, SV: Sample variance, CI: Coefficient of Interval, CV Coefficient Variance 


\section{Conclusion}

Ethiopia is susceptible to climate variability and change, and climate change is occurred every ten years. The effects of climate change may exacerbate existing social and economic encounters across the country, mainly where people are reliant on resources that are sensitive to climate variability and summer rain-fed agriculture. Improved capacity to cope with future climate variability extremes can lessen the extent of economic, social and human loss. Precipitation and temperature are one of the most determinant climate patters for the country, because more than $80 \%$ of the country's agriculture is reliant on rain fed. Increased temperatures, changes in precipitation amounts will increase occurrence of drought and flood events.

Analysis of the 30 years annual precipitation data from Korem representative ground based meteorological station of southern Tigray regional state, showed a coefficient of variation ranging from $33.77-233 \%$. The coefficient of variation underlining the significant variability of precipitation. Though, recorded meteorological data analysis of temperature indicates that increasing trends detected. Regarding to the Mann-Kendall monotonic trend analysis test, the maximum temperature examination bring about in a general warming trend while the minimum mean temperature recorded cooling trend. To suggest that developing countries like Ethiopia in particular are more susceptible to the significant influences of climate variability. This is because of their low adaptive capacity and high sensitivity of their socio-economic systems to climate variability and change. Therefore, the concerned bodies should take in to consideration the precipitation and temperature variability of the area in to their climate change adaptation strategy.

\section{Acknowledgements}

The authors would like to thank Prof.Yingjun Chen, college of Environmental science and engineering, Tongji University for his keen interest and encouragement. The authors are grateful to the UN Environment - Tongji Institute of Environment for sustainable development staffs for their continuous support during this study.

\section{Conflicts of Interest}

The authors declare no conflict of interest.

\section{References}

[1] IPCC, "Synthesis Report. Contribution of Working Group I, II and III to the Fourth Assessment Report of the Intergovernmental Panel on climate change Core writing team. In: Pachauri RK, Reisinger A (eds).," Cambridge Univ. Press 32 Ave. Am. New York, NY 10013-2473, USA, p. 996, 2007.

[2] IPCC, "Managing the risks of extreme events and disasters to advance climate change adaptation. In: A Special Report of Working Groups I and II of the Intergovernmental Panel on Climate Change," Cambridge Univ. Press. Cambridge, United Kingdom New York, NY, USA., 2012.

[3] S. C. Lewis and A. D. King, "Evolution of mean, variance and extremes in 21st century 
temperatures," Weather Clim. Extrem., no. July, p. 1, 2016.

[4] IPCC, "Summary for policymakers. In: Climate Change 2014: Impacts, Adaptation, and Vulnerability. Part A: Global and Sectoral Aspects. Contribution of Working Group II to the Fifth Assessment Report of the Intergovernmental Panel on Climate Change [Field, C.B., ," Cambridge Univ. Press. Cambridge, United Kingdom New York, NY, USA, p. 1-32., 2014.

[5] Baylis M and G. AK, “The Effects of Climate Change on Infectious Diseases of Animals," Dep. Trade Ind. UK., p. 35, 2006.

[6] P. K. . Thornton, P. J. . Ericksen, M. H. And, and A. J. CHALLINOR, “Climate variability and vulnerability to climate change: a review.," Glob. Chang. Biol., no. 20, pp. 3313-3328, 2014.

[7] MER, "Climate Change Profile Ethiopia," Netherlands commission for environmental assessment Dutch suitability unit. Netherlands commission for environmental assessment Dutch suitability unit, 2015.

[8] IPCC, "Presentation of Robert Watson, Chair, Intergovernmental Panel on Climate Change, at the Sixth Conference of the Parties to the United Nations Framework Convention on Climate Change," Cambridge Univ. Press 32 Ave. Am. New York, NY 100132473, USA, 2000.

[9] S. Olmos, "Vulnerability and Adaptation to Climate Change: Concepts, Issues, Assessment Methods," Clim. Chang. Knowl. Netw., p. 21, 2001.

[10] D. K. Karpouzos, S. Kavalieratau, and C. Babajimopoulos, "Trend analysis of precipitation data in Piera Region (Greece)," Eur. Water, no. 30, pp. 30-40, 2010.

[11] W. Hare, "Assessment of Knowledge on Impacts of Climate Change - Contribution to the Specification of Art. 2 of the UNFCCC," W ISSENSCHAF TLICHER B EIRA T DER B UND ESREGIERUNG G LOB ALE U MWEL TVERÄND ERUNGEN, 2003.

[12] A. N. Beyene, "Precipitation and Temperature Trend Analysis in Mekelle City , Northern Ethiopia , the Case of Illala Meteorological Station," vol. 5, no. 19, pp. 46-52, 2015.

[13] S. Addisu, Y. G. Selassie, G. Fissha, and B. Gedif, "Time series trend analysis of temperature and rainfall in lake Tana Sub-basin, Ethiopia," Environ. Syst. Res., vol. 4, no. 1, p. $25,2015$.

C 2017 by the authors; licensee Preprints, Basel, Switzerland. This article is an open access article distributed under the terms and conditions of the Creative Commons by Attribution (CC-BY) license (http://creativecommons.org/licenses/by/4.0/). 